\title{
Baicalin reduces blood lipids and inflammation in patients with coronary artery disease and rheumatoid arthritis: a randomized, double-blind, placebo-controlled trial
}

\author{
Yuanxing Hang, Xian Qin ${ }^{*}$ (D), Tianli Ren and Jianing Cao
}

\begin{abstract}
Background: Patients with rheumatoid arthritis (RA) have an increased risk of coronary artery disease (CAD) above the baseline. Baicalin possesses beneficial effects against both RA and CAD, but little is know on its clincial efficacy among patients manifesting both CAD and RA.

Methods: Three hundred seventy four patients with CAD and RA were randomized to receive either $500 \mathrm{mg}$ baicalin or placebo orally everyday for 12 weeks. Lipid profile, cardiotrophin-1 (CT-1), high sensitivity C-reactive protein (hs-CRP), European League Against Rheumatism (EULAR) response were analyzed at the end of study period.

Results: After 12 week treatment, levels of triglycerides, total cholesterol, LDL-cholesterol and apolipoproteins, as well as CT-1 and hs-CRP, were all significantly improved in the baicalin group compared to the placebo group $(1.12 \pm 0.36$ vs $1.87 \pm 0.46 \mathrm{mmol} / \mathrm{L}, 2.87 \pm 1.23$ vs $3.22 \pm 1.07 \mathrm{mmol} / \mathrm{L}, 1.38 \pm 0.41$ vs $1.16 \pm 0.32 \mathrm{mmol} / \mathrm{L}, 1.31 \pm 0.41$ vs $1.23 \pm 0.29 \mathrm{~g} / \mathrm{L}, 42.9 \pm 13.7$ vs $128.4 \pm 24.3 \mathrm{ng} / \mathrm{mL}, 1.64 \pm 0.38$ vs $3.9 \pm 1.4 \mathrm{mg} / \mathrm{dL}$, respectively). Significantly higher proportion of patients in the baicalin group (71\%) reported good/moderate EULAR response than the placebo group (53\%).

Conclusion: Baicalin reduces blood lipids and inflammation in patients with both CAD and RA, supporting its further clinical application.
\end{abstract}

Keywords: Baicalin, Coronary artery disease, Rheumatoid arthritis, Inflammation, Lipids

\section{Background}

Rheumatoid arthritis (RA) is an inflammatory auto-immune disease that combines joint swelling and tenderness with synovial joint degradation [2]. RA patients are at a higher risk of mortality than the general population $[16,29]$, particularly because of their elevated risk of coronary artery disease (CAD) [12]. Accelerated coronary artery atherosclerosis is reported to directly contribute to increased incidences of CAD and even death $[5,9,16]$. Although common risk factors can contribute to $\mathrm{CAD}$ incidences in RA patients and the general

\footnotetext{
* Correspondence: littlewoodqx@126.com

Wuxi No.2 People's Hospital, 68 Zhongshan Road, Wuxi 214000, Jiangsu, China
}

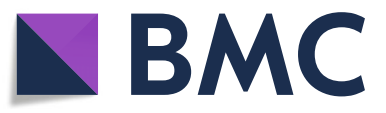

(c) The Author(s). 2018 Open Access This article is distributed under the terms of the Creative Commons Attribution 4.0 International License (http://creativecommons.org/licenses/by/4.0/), which permits unrestricted use, distribution, and reproduction in any medium, provided you give appropriate credit to the original author(s) and the source, provide a link to the Creative Commons license, and indicate if changes were made. The Creative Commons Public Domain Dedication waiver (http://creativecommons.org/publicdomain/zero/1.0/) applies to the data made available in this article, unless otherwise stated.

population, they can not entirely account for the increased CAD events reported in RA patients [7, 18, 25]. A major factor contributing to increased CAD and cardiovascular events in RA patients is probably the elevated systemic inflammation level which are a characteristic RA symptom [26]. In particular, RA-associated inflammation increases risks of CAD by compromising vessel wall integrity, as well as through adversely regulating common risk factors of CAD [23, 28]. Moreover, RA patients in general have marginally higher risk of CAD becaused of their lower levels of cardiorespiratory fitness (CRF) than non-RA individuals [24]. Therefore, therapeutic agents that target both common CAD risk factors and systemic inflammation are 
urgently needed to alleviate CAD risks among RA patients.

Baicalin is a major bioactive ingredient of the traditional Chinese herbal medicine (CHM) Scutellaria baicalensis Georgi. This naturally existing flavone exhibits various pharmacological activity and high clinical value, including anti-inflammatory effects [8]. Baicalin showed specific inhibition against collagenase reaction [19]. In arthritic mouse model, baicalin administration significantly reduced ankle swelling [35]. In addition, in collagen-induced arthritic (CIA) rats, baicalin treatment also relieved joint inflammation [33]. These studies have suggested that baicalin might be a promising novel therapeutic agent for treating RA in humans. On the other hand, baicalin has also exhibited beneficial effects against CAD. For instance, in a chronic pressure-overload mouse model, baicalin suppressed cardiac hypertrophy and fibrosis, thereby attenuating pressure-overload-induced cardiac dysfunction and ventricular remodeling [36]. Moreover, in rats with renovascular hypertension, baicalin reduced pathological changes in the myocardium and myocardial apoptosis, thereby reverting left ventricular remodeling [6]. Baicalin has also been used as anti-arrhythmic and anti-hypertensive drugs in clinical application currently $[14,15]$.

However, to date, no study has been performed on the effects of baicalin on CAD in RA patients. In the current study, we aimed to investigate the therapeutic effect of oral baicalin administration among patients with both CAD and RA.

\section{Methods}

\section{Patients}

In this intention-to-treat study, 374 patients with CAD and RA were recruited at Wuxi No.2 People's Hospital from May 2014 to May 2017. The study was approved by the Ethical Committee of Wuxi No.2 People's Hospital. All participants signed informed consent forms and agreed to our anonymous data utilization policy.

\section{Inclusion and exclusion criteria}

Inclusion criteria were as follows: 1) 45 years of age or older; 2) diagnosed with RA according to the American College of Rheumatology (ACR) criteria [2];3) receiving $\geq 3$ months of unchanged antirheumatic drugs and $\geq$ 1 month of unchanged non-steroidal anti-inflammatory drugs; 4) having moderate or high risk of CAD. A total of 374 patients were initially included in the study.

Exclusion criteria were as follows: 1) having known cerebral, coronary or peripheral artery disease; 2 ) having one or more arthroplasties of weight bearing joints; 3 ) receiving $\geq 3$ months of baicalin supplement prior to joining the study. CAD risk was determined based on age and the presence of CAD risk factors (smoking, hypertension, obesity, diabetes, etc). For the purpose of this study, males 45 years of age or older or males younger than 45 years with two or more CVD risk factors are considered to be at moderate risk of CVD [10]. Females 55 years of age or older or females younger than 55 years with two or more CAD risk factors are considered to be at moderate risk of CVD [10]. Only individuals who have signs or symptoms of CAD or have been diagnosed with $\mathrm{CAD}$ are considered at high risk. High-risk CAD individuals are only eligible to participate in the study if they have not been prescribed statin for any reason. A total of 23 patients were excluded.

\section{Study design}

The remaining 351 eligible patients were then randomized by a permuted-block design stratified to their baseline EULAR into two treatment groups: 1) baicalin group $(n=175)$, who were orally administered $500 \mathrm{mg}$ baicalin on a daily basis for a period of 12 weeks; 2) placebo group $(n=176)$, who were orally administered placebo on a daily basis for 12 weeks. Both baicalin and placebo were provided to all patients in closed labels to make the contents blind to both the patients and the investigators. All patients were also prescribed $20 \mathrm{mg}$ atorvastatin via oral administration once daily, and $8 \mathrm{mg} / \mathrm{kg}$ tocilizumab i.v. every 4 weeks. All patients were instructed not to consume any medication containing baicalin during the 12 week study period. All patients were visited on a monthly basis to ensure compliance to the study protocol. During the 12 weeks study period, 9 patients in the baicalin group and 11 patients in the placebo group, respectively, were withdrawn from the study due to non-compliance or personal reasons, whose data were excluded from the final analysis.

\section{Evalustions and endpoints}

Fasting peripheral venous blood was collected in the morning before treatment and after 12 weeks of treatment for evaluations of CAD parameters. Levels of total cholesterol (TC), triglycerides (TG), low-density lipoprotein cholesterol (LDL-C), high-density lipoprotein cholesterol (HDL-C), apoprotein $A_{1}\left(\right.$ Apo $\left._{1}\right)$ and $B_{100}$ $\left(A p o B_{100}\right)$, high sensitivity-C reactive protein (hs-CRP) and cardiotrophin-1 (CT-1) were detected using DXI800 and AU5800 automatic biochemical analyzers (Beckman, United States of America). For RA parameters, the endpoint was defined as the proportion of patients maintaining good/moderate European League Against Rheumatism (EULAR) response, according to previously published standard [1].

\section{Statistial analysis}

Statistical analysis was conducted using the SPSS software (SPSS Inc., USA). Data were presented as mean 


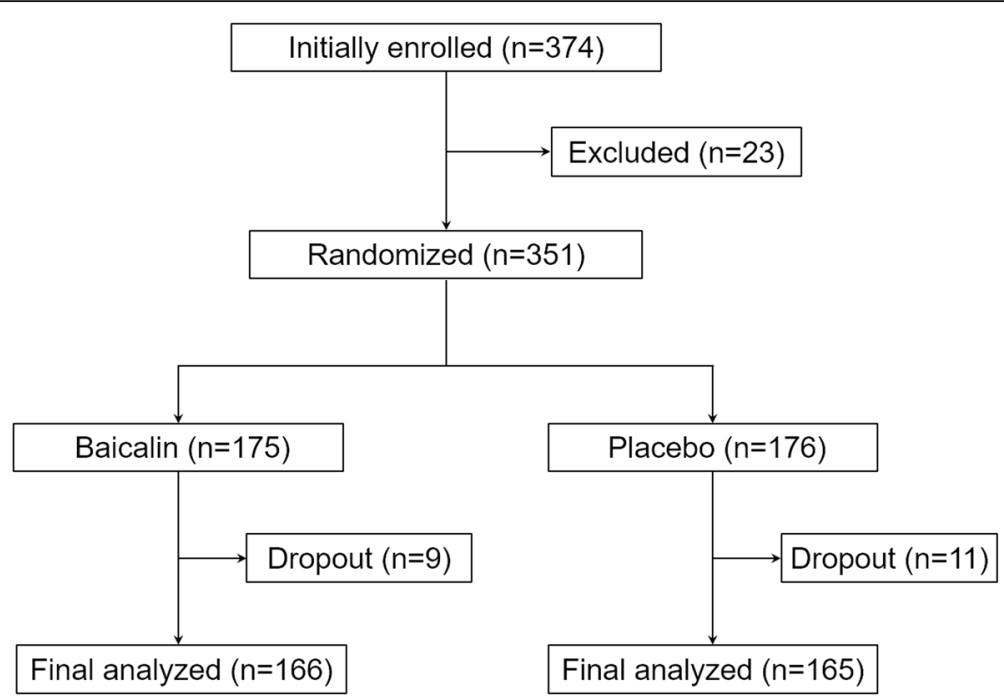

Fig. 1 Randomized study design

\pm standard deviation (SD). The data distribution normality was determined using Kolmogorov-Smirnov goodness-of-fit test. A two-tailed student t-test was employed to calculate significance of normally distributed data, while Mann-Whitney test was employed to calculate significance of non-normally distributed data. $P$ values less than 0.05 were regarded as statistically significant.

\section{Results}

This was an intention-to-treat study, and the randomized study design is shown in Fig. 1. A total of 374 patients were initial recruited into the study, in which 23 were excluded. The remaining 351 patients were then randomized into either baicalin or placebo treatment groups. During the 12 weeks study period, 9 patients in the baicalin group and 11 patients in the placebo group, respectively, were withdrawn from the study due to non-compliance or personal reasons, whose data were excluded from the analysis. Finally, data from 166

Table 1 Baseline characteristics of eligible patients

\begin{tabular}{llll}
\hline & $\begin{array}{l}\text { Baicalin } \\
(n=166)\end{array}$ & $\begin{array}{l}\text { Placebo } \\
(n=165)\end{array}$ & $P$ value \\
\hline Age (years) & $51.3 \pm 4.2$ & $52.1 \pm 5.8$ & $>0.05$ \\
Gender (male/female) & $74 / 92$ & $67 / 98$ & $>0.05$ \\
BMI $\left(\mathrm{kg} / \mathrm{m}^{2}\right)$ & $25.9 \pm 4.1$ & $26.3 \pm 3.7$ & $>0.05$ \\
Smoking $(\mathrm{n})$ & 49 & 57 & $>0.05$ \\
SBP $(\mathrm{mmHg})$ & $143.7 \pm 7.6$ & $148.2 \pm 6.3$ & $>0.05$ \\
DBP $(\mathrm{mmHg})$ & $86.1 \pm 8.3$ & $89.4 \pm 7.8$ & $>0.05$ \\
Time of RA diagnosis (years) & $5.1 \pm 2.4$ & $5.8 \pm 2.9$ & $>0.05$
\end{tabular}

Values are mean \pm SD. BMI body mass index, SBP systolic blood pressure, $D B P$ diastolic blood pressure eligible patients in the baicalin group and 165 eligible patients in the placebo group, respectively, were analyzed. As shown in Table 1, baseline characteristics of all eligible patients from the two treatment groups were listed and compared. We didn't observe any significant differences between the two groups in terms of age, gender, body mass index, smoking, blood pressures and history of RA diagnosis.

Next, we assessed the lipid profile of eligible patients from the two groups (Table 2). In both groups, TG, TC, HDL-C, LDL-C, Apo $A_{1}$ and $\mathrm{ApoB}_{100}$ were all significantly improved after the common treatment of $20 \mathrm{mg}$ atorvastatin via oral administration once daily and $8 \mathrm{mg} / \mathrm{kg}$ tocilizumab i.v. every 4 weeks. Importantly, comparing between the two groups post treatment, all the above parameters were also improved to a better extent in the baicalin group than the placebo group. Similary for CT-1 and hs-CRP levels, marked improvements were also observed

Table 2 Changes in lipid profile of eligible patients before and after treatment

\begin{tabular}{|c|c|c|c|c|}
\hline & \multicolumn{2}{|c|}{ Baicalin $(n=166)$} & \multicolumn{2}{|c|}{ Placebo $(n=165)$} \\
\hline & Baseline & Post treatment & Baseline & Post treatment \\
\hline /L) & $2.77 \pm 1.26$ & $1.12=$ & $2.83 \pm 1.35$ & 1.87 \\
\hline TC $(\mathrm{mmol} / \mathrm{L})$ & $4.62 \pm 1.53$ & $2.87 \pm 1.23 *$ & $4.75 \pm 1.62$ & $3.22 \pm 1.07 * \#$ \\
\hline $\mathrm{HDL}-\mathrm{C}(\mathrm{mmol} / \mathrm{L})$ & $0.96 \pm 0.35$ & $1.38 \pm 0.41 *$ & $1.02 \pm 0.24$ & $1.16 \pm 0.32$ *\# \\
\hline LDL-C (mmol/L) & $2.84 \pm 0.71$ & $1.73 \pm 0.52 *$ & $2.91 \pm 0.83$ & $2.42 \pm 0.57$ *\# \\
\hline $\mathrm{ApoA}_{1}(\mathrm{~g} / \mathrm{L})$ & $1.13 \pm 0.22$ & $1.31 \pm 0.41 *$ & $1.16 \pm 0.27$ & $1.23 \pm 0.29$ *\# \\
\hline $\operatorname{ApoB}_{100}(\mathrm{~g} / \mathrm{L})$ & $0.83 \pm 0.21$ & $0.43 \pm 0.11 *$ & $0.86 \pm 0.25$ & $0.67 \pm 0.23 * \#$ \\
\hline
\end{tabular}

Values are mean \pm SD. ${ }^{*} p<0.05$ compared to baseline within the same group; $\# p<0.05$ compared at the same time point between two groups. TG triglycerides, TC total cholesterol, HDL-C high-density lipoprotein cholesterol, $L D L-C$ low-density lipoprotein cholesterol, $A p o A_{1}$, apolipoprotein $\mathrm{A}_{1}, A p o B_{100}$ apolipoprotein $\mathrm{B}_{100}$ 
Table 3 Changes in CT-1 and hs-CRP levels of eligible patients before and after treatment

\begin{tabular}{llllll}
\hline & \multicolumn{2}{l}{ Baicalin $(n=166)$} & & \multicolumn{2}{l}{ Placebo $(n=165)$} \\
\cline { 2 - 3 } \cline { 5 - 6 } & Baseline & Post treatment & & Baseline & Post treatment \\
\hline CT-1 & $194.6 \pm 42.3$ & $42.9 \pm 13.7 *$ & & $187.4 \pm 39.1$ & $128.4 \pm 24.3^{*} \#$ \\
hs-CRP & $32.4 \pm 2.3$ & $1.64 \pm 0.38 *$ & & $30.8 \pm 2.7$ & $3.9 \pm 1.4 * \#$ \\
\hline
\end{tabular}

Values are mean \pm SD. ${ }^{*} p<0.05$ compared to baseline within the same group; $\# p<0.05$ compared at the same time point between two groups. CT-1 cardiotrophin-1, hs-CRP high-sensitivity C-reactive protein

in both groups of eligible patients (Table 3). Moreover, the extent of improvements in the baicalin group was also significantly better than those in the placebo group.

EULAR is an evalutaion standard for RA patients [1], which was used in the current study to assess the efficacy of baicalin against RA symptoms. As shown in Fig. 2, the proportion of patients who managed to maitain good/moderate EULAR in the baicalin group was significantly higher than that in the placebo group. On the other hand, percentage of patients who failed to maintain good/moderate EULAR in baicalin group was also lower than in the placebo group.

\section{Discussion}

RA patients are exposed to higher risk of CAD, partially becaused of their elevated chronic systemic inflammation levels as a result of their RA conditions [26]. RA-induced inflammation was reported to accelerate progression of plaques in the vasculature [23, 28]. RA patients typically have lower CRF, which likely further potentiates their risk of CAD [24]. Therefore, there is an urgent need to lower CAD risk among RA patients.
Dysregulated metabolism of lipids is a major risk factor contributing to CAD. In line with this, therapies that aim to reduce lipid content is important in preventing and treating $\mathrm{CAD}[4,13]$. To date, statins are the majorly accepted lipid-lowering therapeutic agents [3, 20, 30]. However, most lipid-lowering investigations aiming at better clinical efficacy generally achieve their goal using high statin doses, which have led to higher incidence rate of adverse effects [17]. Besides statin, nutraceuticals have also been reported to successfully combat dyslipidaemia when statins and other drugs fail in lipid levels reduction [27].

Chinese herbal medicine (CHM) has been deemed as complementary therapy of modern Western medicine [11]. In fact, CHM has a long history and is widely used in the treatment and prevention of various diseases worldwide. Bioactive ingredients of $\mathrm{CHM}$ have been reported to reduce infarct volume, improve neurological function and promote endogenous neurogenesis after ischemic stroke [21].

In the context of the current study, we aimed to investigate the therapeutic effects of oral baicalin administration among patients with both CAD and RA. After 12 weeks, we found that lipid profiles of CAD and RA patients were significantly improved by $20 \mathrm{mg}$ atorvastatin via oral administration once daily and $8 \mathrm{mg} / \mathrm{kg}$ tocilizumab i.v. every 4 weeks, confirming the effectiveness of this common treatment. Importantly, we observed better improvements in patients treated by baicalin than those on placebo treatment, demonstrating the beneficial effect of baicalin on further improving lipid profile. Moreover, the extent of improvements with

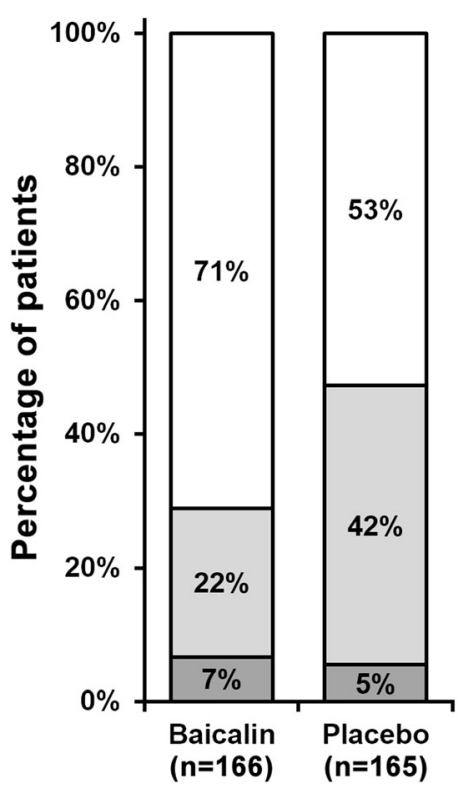

口Maintained good/moderate EULAR

口Failed to maintain good/moderate EULAR

口Unknown 
regard to CT-1 and hs-CRP, two important risk factors of CAD, was also significantly better in the baicalin group than that in the placebo group, further indicating the efficacy of baicalin in alleviating CAD risks. In terms of RA symptom evaluation, we employed the EULAR as the indicator of RA in the present study. It was observed that proportion of patients maitaining good/moderate EULAR in baicalin group was significantly higher than that of placebo group, while percentage of patients failing to maintain good/moderate EULAR in baicalin group was also lower than in the placebo group. These data clearly supported that, besides lowering CAD risks, baicalin also exhibited potent efficacy in attenuating RA symptoms.

Granted that baicalin possesses dual benefical effects against both CAD and RA, yet the underlying molecular mechanism is unclear. Baicalin was reported to reverse the effect of myocardial injury and inflammation in a mouse model of myocardial ischaemic injury [34]. The authors found that administration of baicalin was able to reduce hs-CRP [34], which was consistent with results in our current study. Furthermore in the same study, baicalin was also shown to suppress inflammation by blocking the aryl hydrocarbon receptor (AhR) [34]. Increasing evidences to date have pointed to an importance for AhR in controlling the extent of inflammatory reactions in response to heart diseases in animal models [22, 31, 32], and it would be interesting to test whether AhR was also affected by baicalin in clinical settings.

In the context of RA, baicalin administration significantly reduced ankle swelling in an arthritic mouse model [35]. In the same study, baicalin treatment also inhibited splenic Th17 cell population expansion. Investigations into the underlying molecular mechanism have indicated that, baicalin could inhibit expression of RORgt gene, a key transcription factor in the differentiation of Th17 cells. Baicalin treatment in an IL-17-contaminated synoviocytes culture greatly suppressed the adhesion of lymphocytes to synoviocytes, and inhibited the inflammatory cascade following IL-17 induction, as well as downregulated expressions of pro-inflammatory cytokines [35]. In addition, baicalin could alleviate joint inflammation in CIA rats by suppressing synovial expression of NF-kB p65 subunit [33]. Future studies are needed to investigate the effects of baicalin on the above RA-related factors among patients, to further understand the pharmarcology of baicalin.

\section{Conclusion}

To conclude, our study hereby supports the clinical efficacy of baicalin in reducing blood lipids and inflammation in patients with both CAD and RA.

\section{Abbreviations}

CAD: coronary artery disease; CT-1: cardiotrophin-1; hs-CRP: high sensitivity C-reactive protein; RA: Patients with rheumatoid arthritis
Availability of data and materials

All data generated or analysed during this study are included in this published article.

\section{Authors' contributions}

Concept/design; data interpretation; drafting article; critical revision of article; approval of article: XQ; data analysis/interpretation/collection; critical revision of article; approval of article: YH, TR, JC.

\section{Ethics approval and consent to participate}

All procedures performed in studies involving human participants were in accordance with the ethical standards of the research committee of Wuxi No.2 People's Hospital and with the 1964 Helsinki declaration and its later amendments or comparable ethical standards.

\section{Consent for publication}

All participants have given consent for publication.

\section{Competing interests}

The authors declare that they have no competing interests.

\section{Publisher's Note}

Springer Nature remains neutral with regard to jurisdictional claims in published maps and institutional affiliations.

Received: 16 May 2018 Accepted: 8 June 2018

Published online: 23 June 2018

\section{References}

1. Agca $R$, et al. EULAR recommendations for cardiovascular disease risk management in patients with rheumatoid arthritis and other forms of inflammatory joint disorders: 2015/2016 update. Ann Rheum Dis. 2017;76:17-28. https://doi.org/10.1136/annrheumdis-2016-209775.

2. Aletaha D, et al. 2010 rheumatoid arthritis classification criteria: an American College of Rheumatology/European league against rheumatism collaborative initiative. Arthritis Rheum. 2010;62:2569-81. https://doi.org/10. 1002/art.27584.

3. Balk EM, Lau J, Goudas LC, Jordan HS, Kupelnick B, Kim LU, Karas RH. Effects of statins on nonlipid serum markers associated with cardiovascular disease: a systematic review. Ann Intern Med. 2003;139:670-82.

4. Benn M. Apolipoprotein B levels, APOB alleles, and risk of ischemic cardiovascular disease in the general population, a review. Atherosclerosis. 2009;206:17-30. https://doi.org/10.1016/j.atherosclerosis.2009.01.004.

5. Chung CP, et al. Increased coronary-artery atherosclerosis in rheumatoid arthritis: relationship to disease duration and cardiovascular risk factors. Arthritis Rheum. 2005;52:3045-53. https://doi.org/10.1002/art.21288.

6. Dai H, Zhang X, Yang Z, Li J, Zheng J. Effects of Baicalin on blood pressure and left ventricular remodeling in rats with Renovascular hypertension. Med Sci Monit. 2017;23:2939-48.

7. del Rincon ID, Williams K, Stern MP, Freeman GL, Escalante A. High incidence of cardiovascular events in a rheumatoid arthritis cohort not explained by traditional cardiac risk factors. Arthritis Rheum. 2001;44:2737-45.

8. Dinda B, Dinda S, DasSharma S, Banik R, Chakraborty A, Dinda M. Therapeutic potentials of baicalin and its aglycone, baicalein against inflammatory disorders. Eur J Med Chem. 2017;131:68-80. https://doi.org/10. 1016/j.ejmech.2017.03.004.

9. Erb N, Pace AV, Douglas KM, Banks MJ, Kitas GD. Risk assessment for coronary heart disease in rheumatoid arthritis and osteoarthritis. Scand J Rheumatol. 2004;33:293-9. https://doi.org/10.1080/03009740410006899.

10. Ferguson B (2014) ACSM's guidelines for exercise testing and prescription 9th Ed 2014. J Can Chiropractic Assoc 58:328-328.

11. Fleischer T, Chang T, Chiang JH, Hsieh CY, Sun MF, Yen HR. Integration of Chinese herbal medicine therapy improves survival of patients with chronic lymphocytic leukemia: a Nationwide population-based cohort study. Medicine (Baltimore). 2016;95:e3788. https://doi.org/10.1097/MD. 0000000000003788.

12. Goodson N. Coronary artery disease and rheumatoid arthritis. Curr Opin Rheumatol. 2002;14:115-20.

13. Hansson GK. Inflammation, atherosclerosis, and coronary artery disease. N Engl J Med. 2005;352:1685-95. https://doi.org/10.1056/NEJMra043430. 
14. Huang $\mathrm{WH}$, Lee $\mathrm{AR}$, Yang $\mathrm{CH}$. Antioxidative and anti-inflammatory activities of polyhydroxyflavonoids of Scutellaria baicalensis GEORGI. Biosci Biotechnol Biochem. 2006;70:2371-80. https://doi.org/10.1271/bbb.50698.

15. Huang Y, Tsang SY, Yao X, Chen ZY. Biological properties of baicalein in cardiovascular system. Curr Drug Targets Cardiovasc Haematol Disord. 2005:5:177-84

16. Kaplan MJ. Cardiovascular complications of rheumatoid arthritis: assessment, prevention, and treatment. Rheum Dis Clin N Am. 2010;36:405-26. https://doi.org/10.1016/j.rdc.2010.02.002.

17. Koh KK, Quon MJ, Han SH, Lee Y, Kim SJ, Shin EK. Atorvastatin causes insulin resistance and increases ambient glycemia in hypercholesterolemic patients. J Am Coll Cardiol. 2010;55:1209-16. https://doi.org/10.1016/j.jacc.2009.10. 053

18. Kozera L, Andrews J, Morgan AW. Cardiovascular risk and rheumatoid arthritis-the next step: differentiating true soluble biomarkers of cardiovascular risk from surrogate measures of inflammation. Rheumatology (Oxford). 2011;50:1944-54. https://doi.org/10.1093/rheumatology/ker232.

19. Lee $J H$, Kim GH. Evaluation of antioxidant and inhibitory activities for different subclasses flavonoids on enzymes for rheumatoid arthritis. J Food Sci. 2010;75:H212-7. https://doi.org/10.1111/j.1750-3841.2010.01755.x.

20. Lewis SJ. Lipid-lowering therapy: who can benefit? Vasc Health Risk Manag. 2011;7:525-34. https://doi.org/10.2147/NHRM.S23113.

21. $\mathrm{Li} \mathrm{JH}$, et al. Bioactive components of Chinese herbal medicine enhance endogenous neurogenesis in animal models of ischemic stroke: a systematic analysis. Medicine (Baltimore). 2016;95:e4904. https://doi.org/10. 1097/MD.0000000000004904.

22. Lund AK, Goens MB, Kanagy NL, Walker MK. Cardiac hypertrophy in aryl hydrocarbon receptor null mice is correlated with elevated angiotensin II, endothelin-1, and mean arterial blood pressure. Toxicol Appl Pharmacol. 2003:193:177-87

23. Mahmoudi M, Aslani S, Fadaei R, Jamshidi AR. New insights to the mechanisms underlying atherosclerosis in rheumatoid arthritis. Int J Rheum Dis. 2017;20:287-97. https://doi.org/10.1111/1756-185X.12999.

24. Metsios GS, et al. Cardiorespiratory fitness levels and their association with cardiovascular profile in patients with rheumatoid arthritis: a cross-sectional study. Rheumatology (Oxford). 2015;54:2215-20. https://doi.org/10.1093/ rheumatology/kev035.

25. Rho $\mathrm{YH}$, et al. Inflammatory mediators and premature coronary atherosclerosis in rheumatoid arthritis. Arthritis Rheum. 2009;61:1580-5. https://doi.org/10.1002/art.25009.

26. Sattar N, McCarey DW, Capell H, Mclnnes IB. Explaining how "high-grade" systemic inflammation accelerates vascular risk in rheumatoid arthritis. Circulation. 2003;108:2957-63. https://doi.org/10.1161/01.CIR.0000099844. 31524.05 .

27. Scicchitano P, et al. Nutraceuticals and dyslipidaemia: beyond the common therapeutics. J Funct Foods. 2014;6:11-32. https://doi.org/10.1016/j.jff.2013. 12.006.

28. Skeoch S, Bruce IN. Atherosclerosis in rheumatoid arthritis: is it all about inflammation? Nat Rev Rheumatol. 2015;11:390-400. https://doi.org/10.1038/ nrrheum.2015.40.

29. Sokka T, Abelson B, Pincus T. Mortality in rheumatoid arthritis: 2008 update. Clin Exp Rheumatol. 2008;26:S35-61.

30. Stone NJ, et al. 2013 ACC/AHA guideline on the treatment of blood cholesterol to reduce atherosclerotic cardiovascular risk in adults: a report of the American College of Cardiology/American Heart Association task force on practice guidelines. J Am Coll Cardiol. 2014;63:2889-934. https://doi.org/ 10.1016/j.jacc.2013.11.002.

31. Thackaberry EA, Gabaldon DM, Walker MK, Smith SM. Aryl hydrocarbon receptor null mice develop cardiac hypertrophy and increased hypoxiainducible factor-1alpha in the absence of cardiac hypoxia. Cardiovasc Toxicol. 2002;2:263-74.

32. Vasquez A, Atallah-Yunes N, Smith FC, You X, Chase SE, Silverstone AE, Vikstrom KL. A role for the aryl hydrocarbon receptor in cardiac physiology and function as demonstrated by AhR knockout mice. Cardiovasc Toxicol. 2003;3:153-63.

33. Wang $\mathrm{HZ}$, et al. Inhibitory effect of baicalin on collagen-induced arthritis in rats through the nuclear factor-kappaB pathway. J Pharmacol Exp Ther. 2014;350:435-43. https://doi.org/10.1124/jpet.114.215145.

34. Xue $Y$, et al. Baicalin inhibits inflammation and attenuates myocardial ischaemic injury by aryl hydrocarbon receptor. J Pharm Pharmacol. 2015;67:1756-64. https://doi.org/10.1111/jphp.12484
35. Yang $X$, Yang J, Zou H. Baicalin inhibits IL-17-mediated joint inflammation in murine adjuvant-induced arthritis. Clin Dev Immunol. 2013;2013:268065. https://doi.org/10.1155/2013/268065.

36. Zhang Y, Liao P, Zhu M, Li W, Hu D, Guan S, Chen L. Baicalin attenuates cardiac dysfunction and myocardial remodeling in a chronic pressureoverload mice model. Cell Physiol Biochem. 2017;41:849-64. https://doi.org/ $10.1159 / 000459708$

\section{Ready to submit your research? Choose BMC and benefit from:}

- fast, convenient online submission

- thorough peer review by experienced researchers in your field

- rapid publication on acceptance

- support for research data, including large and complex data types

- gold Open Access which fosters wider collaboration and increased citations

- maximum visibility for your research: over $100 \mathrm{M}$ website views per year

At BMC, research is always in progress.

Learn more biomedcentral.com/submissions 